\title{
Digital Tipping Point: The Balance of Priority between Traditional and Digital Journalism Skills at Local UK Newspapers
}

\author{
Rebecca Lucy Whittington \\ Journalism Department, Leeds Trinity University, UK
}

Copyright $(2016$ by authors, all rights reserved. Authors agree that this article remains permanently open access under the terms of the Creative Commons Attribution License 4.0 International License.

\begin{abstract}
A recruitment advertisement shines a light on what an organization is looking for not only in a new employee, but also in existing staff members. It projects the values, aims and direction of an organization, reflecting ambitions that may not be fully representative of the existing reality. In the turbulent UK local newspaper industry there has been a sea change in methods of collecting, reporting and, from the audience perspective, consuming the news. However, until recently, studies have found traditional reporting skills are prized more highly than online skills by newspaper managers. Working to the hypothesis that this will have changed, with digital media skills being equally, if not more, desired than traditional journalistic skills, this paper assesses the language of recruitment advertisements for local newspaper journalist roles on www.holdthefrontpa ge.co.uk from November 2014 to January 2015. Using a set of 'traditional' keywords and a set of 'digital' keywords, the priority of their use and the tone of their delivery will show the corporate ideal being projected. In turn, this will demonstrate the desired state of the individual titles, their mother companies and the industry as a whole.
\end{abstract}

Keywords Newspapers, UK, Skills, Journalism, News, Digital, Traditional

\section{Introduction}

"As the qualities for achieving prominence change, so the prominent men change" [1].

What industry has been so wracked by change and managed to survive as that of making the news? As documented, discussed and pondered by commentators, practitioners and academics, for nigh on two decades, news and newspapers have been subject to turbulent change and flux thanks to the internet and digitisation. As part of that process, reluctance to adapt to digital change has been evident from research carried out in newsrooms over the past decade [2-5].

Along with the rise of the internet there has been the development of technology which has allowed journalists to work faster, more effectively and with better results. This same technology has shifted the landscape of journalism and has broadened the skill sets needed by journalists [6-7]. Not only that, but the availability of digital technology and the way it is used by the general public has changed dramatically - with $55 \%$ of adults in the UK using the internet to read or download news, newspapers or magazines in 2014 - up from just $20 \%$ in 2007 [8].

But despite the introduction of websites, social media, online competitors, video and audio packages, blogs and smartphones - to name just a few digital innovations surprisingly the value placed on skills possessed by new recruits to the newspaper industry have changed very little $[2,4,5,9,10]$. Only in the past couple of years have editors started to indicate that digital skills may have a comparable value to those possessed traditionally by journalists. But despite acknowledgement that digital skills may have value, editors have so far refrained from placing precedence on digital skills over traditional journalistic abilities [11,12].

This research, focusing on local newspapers within the UK, bucks that trend. The findings from data collected over a three month period from one of the main employment and news websites for local newspapers within the UK indicates digital skills have finally surpassed traditional ones in terms of desirability and importance.

There is caution to be voiced in the fact that this data set is from a limited source taken from a brief snapshot of time; it is only the start of a four year study designed to map skills requirements in local UK newspapers. However, it cannot be overlooked that the results from this brief time period suggest digital skills may finally be regarded by employing editors as important, if not more important, than the ones so prized traditionally. Has the tipping point finally been reached? 


\section{Literature Review}

When Sheller investigated how digital technology has changed the process of news production in local and regional newspapers, she described how social media, smartphones, the internet and its flow of information, had changed the production of "yesterday's news" into "news now" [13].

Her account is a concise summary of a situation that scholars have been probing for the past decade and more that the landscape of printed news has not only been subject to fundamental change due to the introduction of digital technology, but it continues to change at a startling rate and in an unpredictable manner [6, 14-16].

The shift from print-only to digital convergence now sees a world in which newspapers have numerous 'platforms' and judge their merits and successes based on web-hits as well as newspaper sales [17-19].

Print journalists have expanded their skill sets to include capabilities such as the production of online video, the use of social media and using the internet to break news online as it happens, rather than waiting for the newspaper to hit the stands the following morning.

But despite this change, much academic research has so far suggested that while a shift in values is gradually happening, traditional skills have still been significantly more highly valued by employing editors than digital skills.

A study by Russial and Santana [5] found that while multi-media skills and convergence between online skills and traditional reporting skills were being sought to a degree by newspaper managers, traditional skills were still more highly prized among general news staff. They concluded:

The skills most valued across the board are the same skills that have been valued for a long time. Other skills, such as the multimedia skills that are at the core of curricular change, map much more closely onto specialist positions than on news staff in general. [5]

Research carried out by Carpenter [4] found non-technical, traditional news journalism skills were more highly listed in job advertisements for journalists working in online media than technical skills. However, the study noted that while only 23.8 per cent of journalism recruitment adverts specified social media skills as being desirable in a job applicant, the requirement for that particular skill would be likely to increase over time.

Longitudinal research by Cleary and Cochie [9] found the same - that despite technology changing, the core skills required in the newsroom were traditional. This stance was echoed by research by the National Council of the Training for Journalists (NCTJ) which decided against changing its curriculum based on results that showed a preference by editors for traditional skills [10].

And Pierce and Miller found that while the importance of converged skills had increased, "the old standards remain at the top of the list of importance for most editors" [2].

Although there has been the acknowledgement that social media skills are "no longer optional" for local newspaper journalists [20], it seems that up to a point, history has been shaping the future, with traditional journalistic skills and methods still being more highly valued even in a setting changed by technology [21-23].

However, more recently there has been evidence to suggest that values may be changing.

According to Bradley [24], journalists need to "rethink our approach to how we do our jobs", with coding and data knowledge increasing in importance.

A newsroom study found older journalists felt unsettled and concerned about the future as well as finding themselves overlooked for promotion in favor of younger staff who were perceived to think more digitally [11].

At least one regional newspaper group has set up a data department [25] and a recent study [12] found employing editors prized traditional journalistic skills equally to digital skills.

So have attitudes changed? And how can this be measured? This study looks particularly at local UK newspapers due to a gap in research in the area.

This researcher believes attitudes have changed, with the hypothesis that this study will show:

H1. Traditional journalism skills and values are valued equally or even less than digital skills by regional UK newspapers recruiting for news positions.

This can be investigated by the research question:

R1. Do recruitment advertisements for local news journalists place more, equal or less emphasis on digital reporting skills and values in comparison to traditional journalism skills?

\section{Method}

Job advertisements are a reflection of a company's brand, values, aims and intentions, even if those aims are "a desired future state, rather than a current reality" [26]. The composition of a recruitment advertisement not only shows an organisation in its best and most ideal light [27], but also highlights the values via which the company defines its "means of achieving an outcome" [28].

Therefore, by assessing the language of recruitment advertisements for news journalists placed by regional and local UK newspapers it should be possible to analyse what skills are being sought in terms of ideal candidates and in turn, the "desired state" of the recruiting newsroom and business. This will help show the impact of the use of digital tools in terms of the desirability of employees with digital skills and, in turn, will shine a light onto the values of that company. The results will also demonstrate the weight of importance placed on digital skills when compared with traditional journalism skills.

This study is focused solely on recruitment advertising featured on www.holdthefrontpage.co.uk (HTFP) - a website which caters primarily for local and regional newspaper journalists within the UK.

The term "regional newspaper" can be defined as a newspaper and its affiliated digital platforms (website, 
social media and other digital products) which serves a local town, city or region. It is usually owned by a larger publishing company, which may have numerous local newspapers within its portfolio. With a couple of exceptions, regional weekly newspapers often have a handful of staff many of whom work across more than one newspaper title within the same news group. Daily regional papers tend to have more staff and often share some content with affiliated weekly titles. Both daily and weekly titles have suffered massive staffing cuts over the past decade and their circulation can range from around 4,000 people to 80,000 depending on the area covered and the success of the title.

This study found that three of the four major regional UK news groups (Trinity Mirror, Newsquest and Local World) and a number of smaller regional newspaper publishers advertise positions via HTFP. The website is well-known among regional newspaper journalists as being the place to find job advertisements and as a result it is the first port of call for most journalists looking for work in the regional newspaper industry within the UK. Regional newspapers within the UK tend not to advertise anywhere but HTFP, with the exception of the Press Gazette, which also runs recruitment advertisements for various news outlets online. However, as the Press Gazette only occasionally advertises for positions within regional newspapers - instead focusing more on national titles and magazines - this study focuses solely on HTFP as including the Press Gazette was not considered to have the potential to offer significant contribution to the research.

Over a period of three months, from November 1, 2014 to January 31,2015 , all recruitment advertisements placed on HTFP for news journalist positions within UK local newspapers were collected. The collection included all levels of employment ranging from editor, deputy editor, newsdesk, specialist reporter, reporter and trainee reporter. Collection did not include features writers or sports journalists and also excluded adverts for positions anywhere other than local and regional newspapers within the UK.

A traditional keyword set and a digital keyword set were identified - with 19 words in each set. The keywords were identified through various methods. The author of the study partially drew on her recent experience of her time as an editor at regional newspapers, during which she advertised for several journalists via HTFP. This experience gave a broad overview of both the traditional and digital skills required in a working newsroom. Both skill sets were also identified through assessment of other research studies in which skill sets had been assessed or employing editors questioned about valued attributes of news journalists $[2,10,12]$ and through studying advertisements for journalism positions.

The traditional words were selected on the basis that they identified skills and qualities associated with news journalism prior to the introduction of digital technology. The keywords are:

Deadline, pressure, contacts, driving license, NCE,
NCTJ, NQJ, shorthand, qualifications, print, copy, tight, writing, enthusiasm, self-starter, exclusive, energy, ideas, news sense.

The digital keywords were selected on the basis that they identified skills and qualities directly associated with the introduction of digital technology in the newsroom. The keywords are:

Digital, multi-media, platforms, website, social media, UGC/user-generated content, breaking news, data, Twitter, Facebook, online, web skills, hits, unique user, visitor, likes, blog, code, video, podcast.

Variance in keywords was allowed for so long as the meaning or use was not changed by the difference, for example deadline/deadlines and multi-media/multimedia.

It must be noted that while the majority of keywords could be described as qualities or subjects rather than specific skills, their inclusion within the advertisement reflects the need for successful candidates to have the skills which are relevant to those qualities and subjects. For example, the word 'Facebook' is not a skill in its own right - but when included in a sentence reading 'the successful candidate must have a proficient knowledge of Facebook' it becomes the key word in a sentence describing a required skill.

The advertisements, once collected, were subjected to content analysis using the keywords. Only the main job description of the advert was used - with the job title and additional details being excluded from analysis. Each advert was analyzed for inclusion of traditional words and digital words. The number of times a keyword appeared in the text was noted, along with where in the text the first instance of that keyword was placed. A record of the keywords appearing first in the text was made, as literature shows recruitment advertisements are usually written with key skills and qualities listed in order of importance [29].

Adverts were also analyzed for job type as identified in categories on HTFP, with the following code being used:

Editor: E, Deputy Editor: DE, News Editor/Newsdesk position: NE, Specialist Reporter: SE, Reporter: R, Trainee Reporter: TR, Online Journalist: OJ, Other: O.

A note was also made of the employing parent company.

During analysis it became clear that some words had dual meanings, for example the word 'code' in the digital keyword set was to identify web programming skills. However, the same word could also mean a code of conduct, which could be interpreted as having a traditional meaning. Therefore, any inclusion of keywords which were not used in the relevant meaning devised as part of the study were recorded as N/A.

\section{Results}

Over the three month period 102 advertisements were collected, four of which were later dismissed as being ineligible. 
Out of the adverts assessed there was a much higher prevalence of digital keywords over traditional keywords. Overall, traditional keywords appeared in the job descriptions 395 times (44\%) and digital keywords appeared 496 (56\%) times.

The full set of 19 traditional keywords were used in the job descriptions (Figure. 1), with the most popular being 'print', which appeared 58 times, and 'NCTJ', which appeared 55 times. They were followed by 'ideas' with 38 uses, 'driving licence' with 36 and 'writing' with 22.

Of the 19 digital keywords, only 16 were used in the advertisements (Figure. 2), with 'online' being the most popular, appearing 99 times, and 'digital' appearing 98 times. These were followed by 'social media' with 75 uses, 'website' with 67 and 'platforms' with 42 appearances. Those which did not appear were 'likes', 'podcast' and 'code'.

\section{Traditional keyword use}
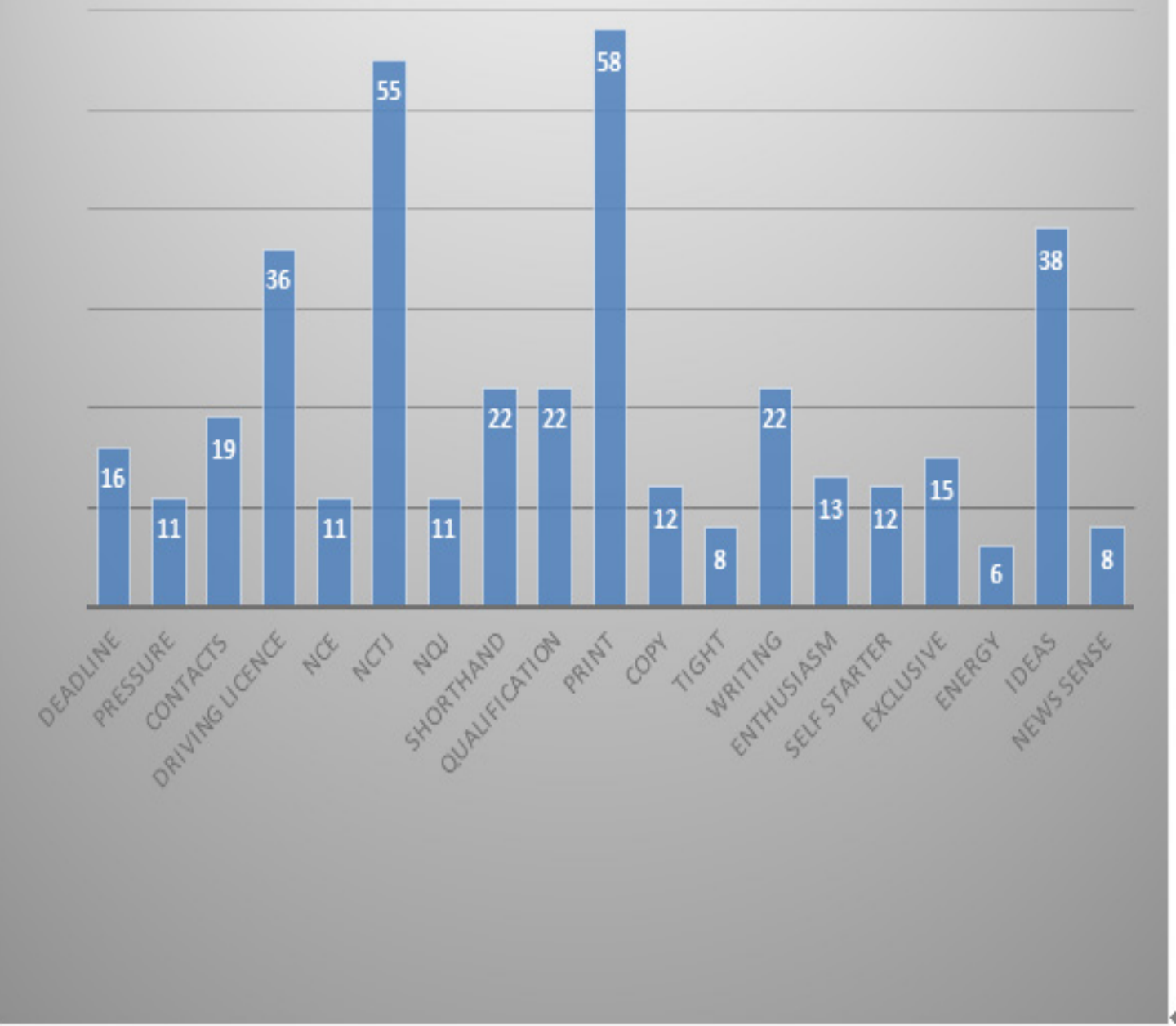

Figure 1. 


\section{Digital keyword use}
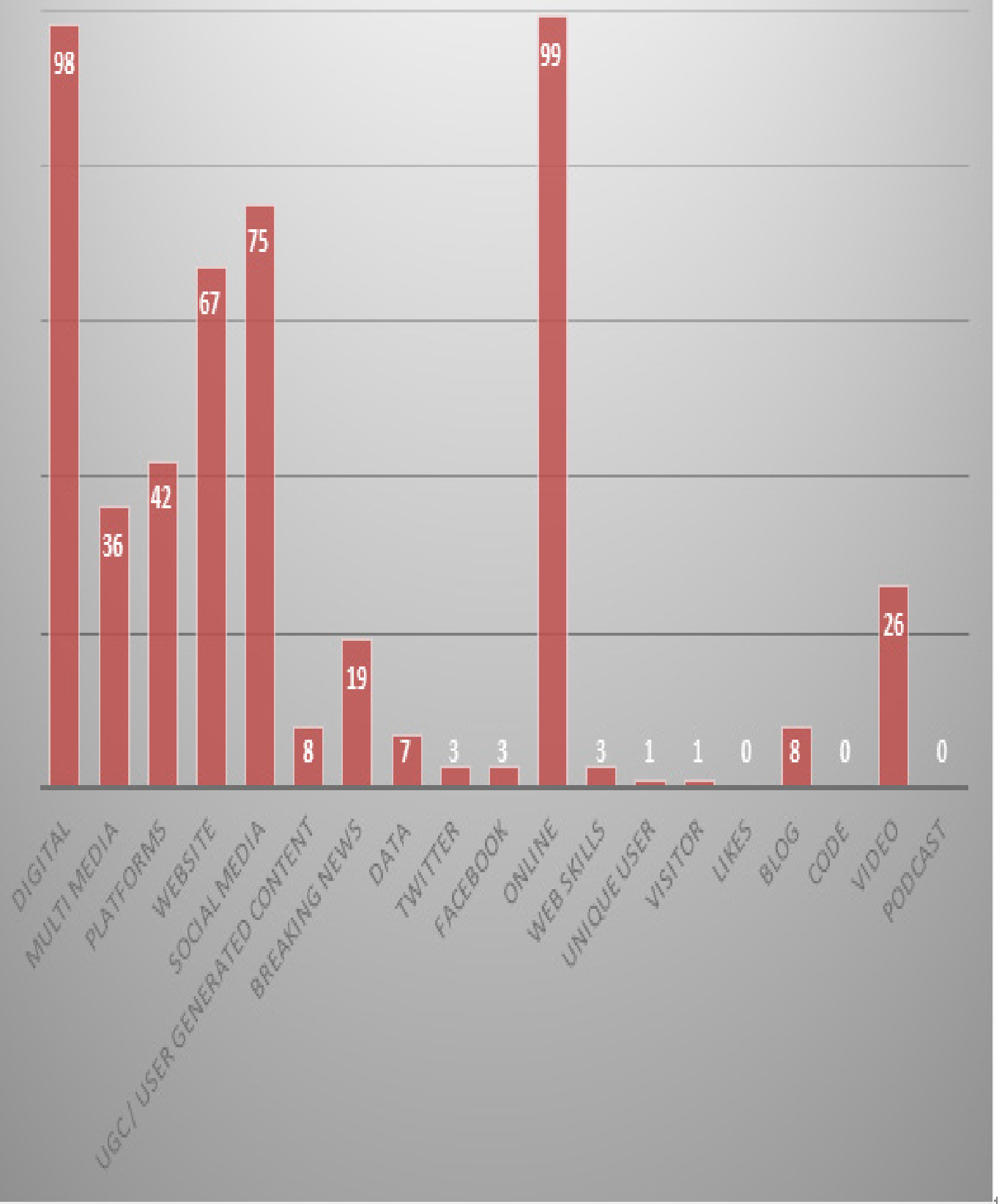

Figure 2.

Of the five keywords given the top priority in terms of being the first out of both keyword sets to appear within the job description, the top three were digital keywords (Figure. 4). They were 'website', 'multimedia' and 'online', followed jointly by traditional words 'print' and 'NCTJ'. 


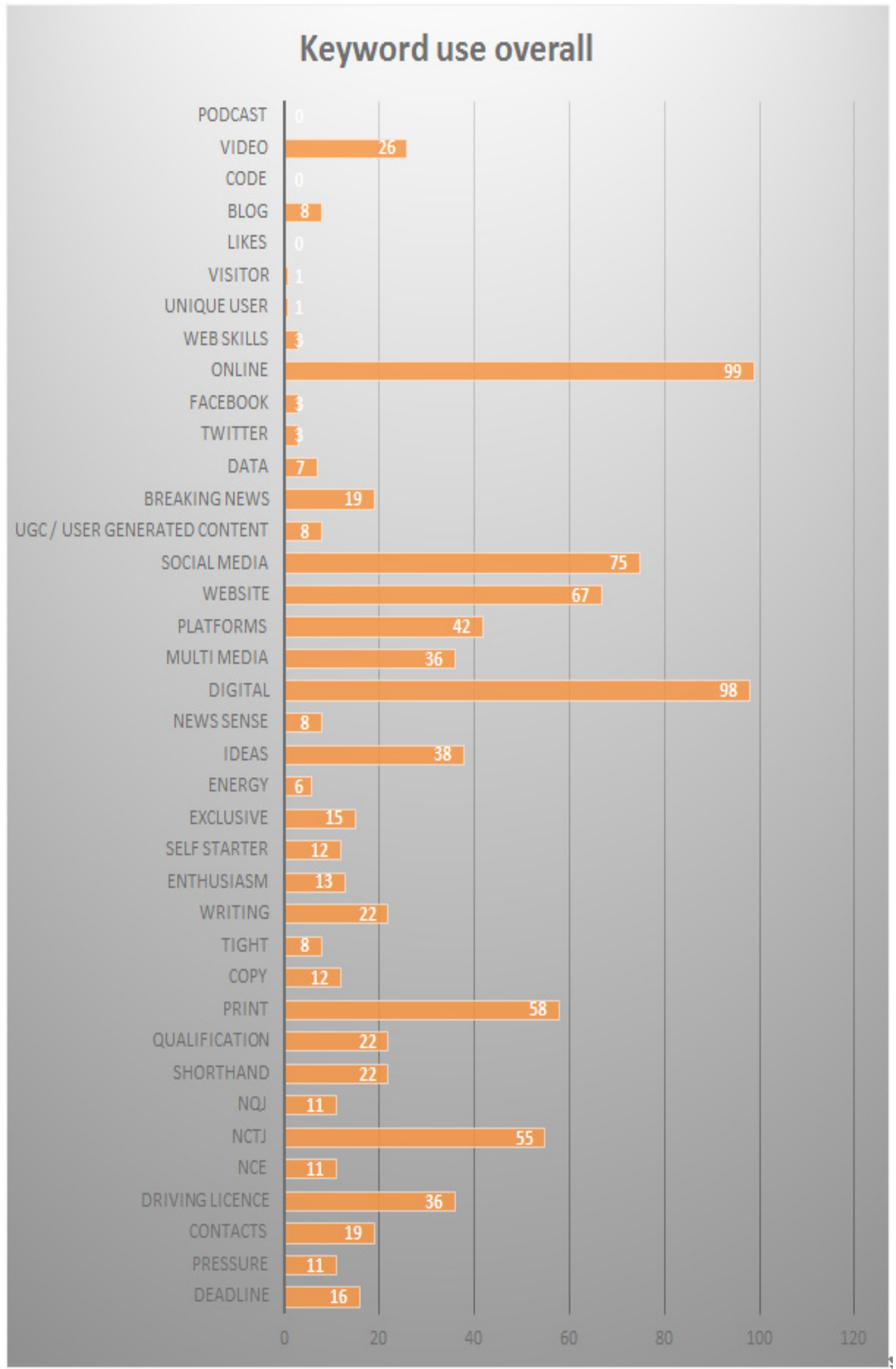

Figure 3. 


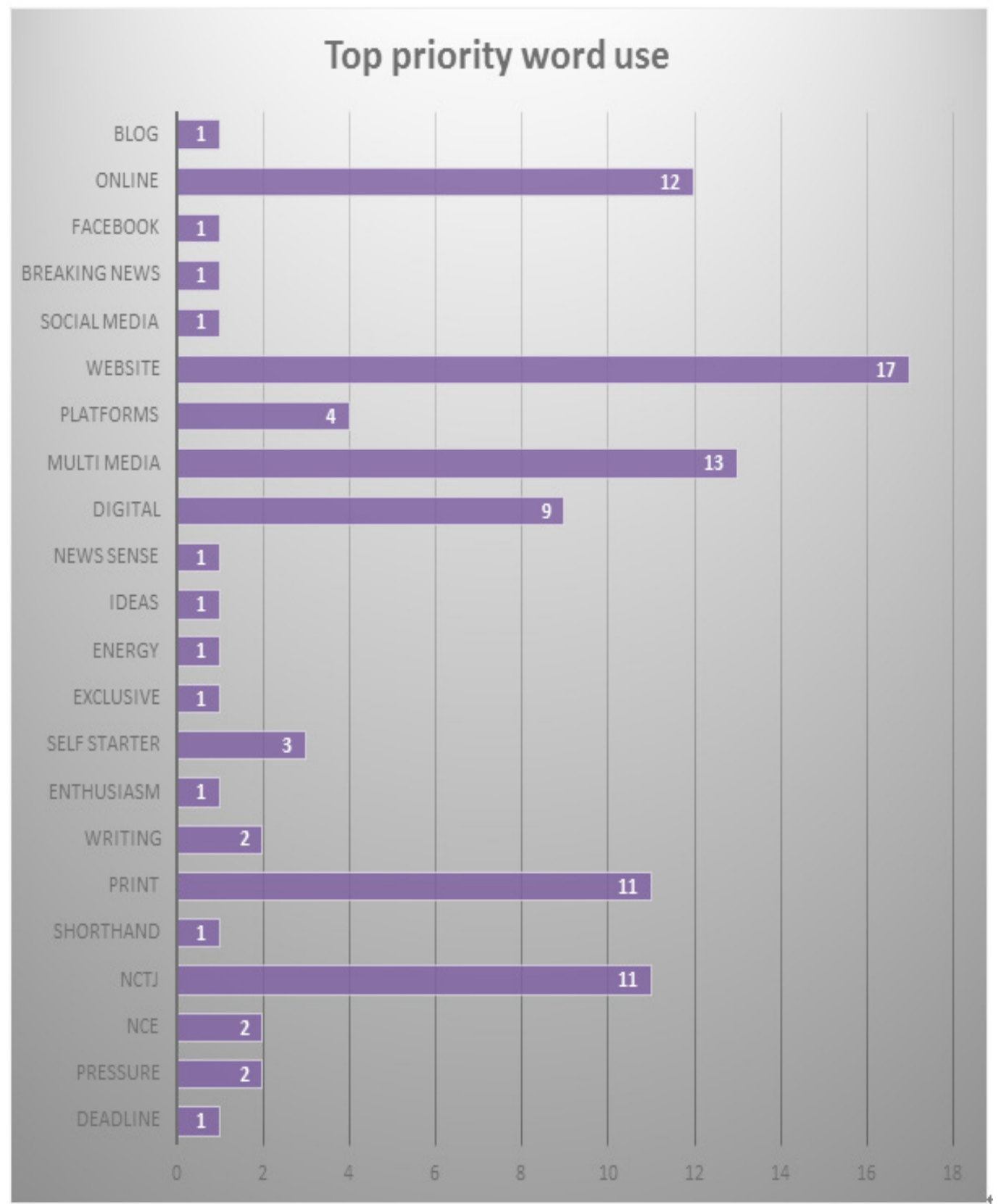

Figure 4.

Local World ran the highest number of recruitment adverts - with 33 placed. It was followed by Newsquest, which ran 22 adverts and then Trinity Mirror, which advertised 16 times. Johnston Press, which completes the set of the four largest newsgroups in the UK, did not run any news journalist recruitment adverts during this time period. Other adverts were run by smaller newsgroups or independently owned newspapers.

Out of the three main newsgroups included in the study Trinity Mirror placed the highest emphasis on digital language, with $73 \%$ of the overall keywords used being from the digital set (Figure. 5). This was followed by Newsquest, with $54 \%$ of the overall keywords being digital and then Local World, with $52 \%$ of the overall keywords used being digital. Archant bucked the trend with $59 \%$ of overall keywords being from the traditional set and the other smaller titles followed the same suit, which when grouped together (due to many placing only one or two adverts) had $70 \%$ of overall keywords from the traditional set and only $30 \%$ from the digital set. 


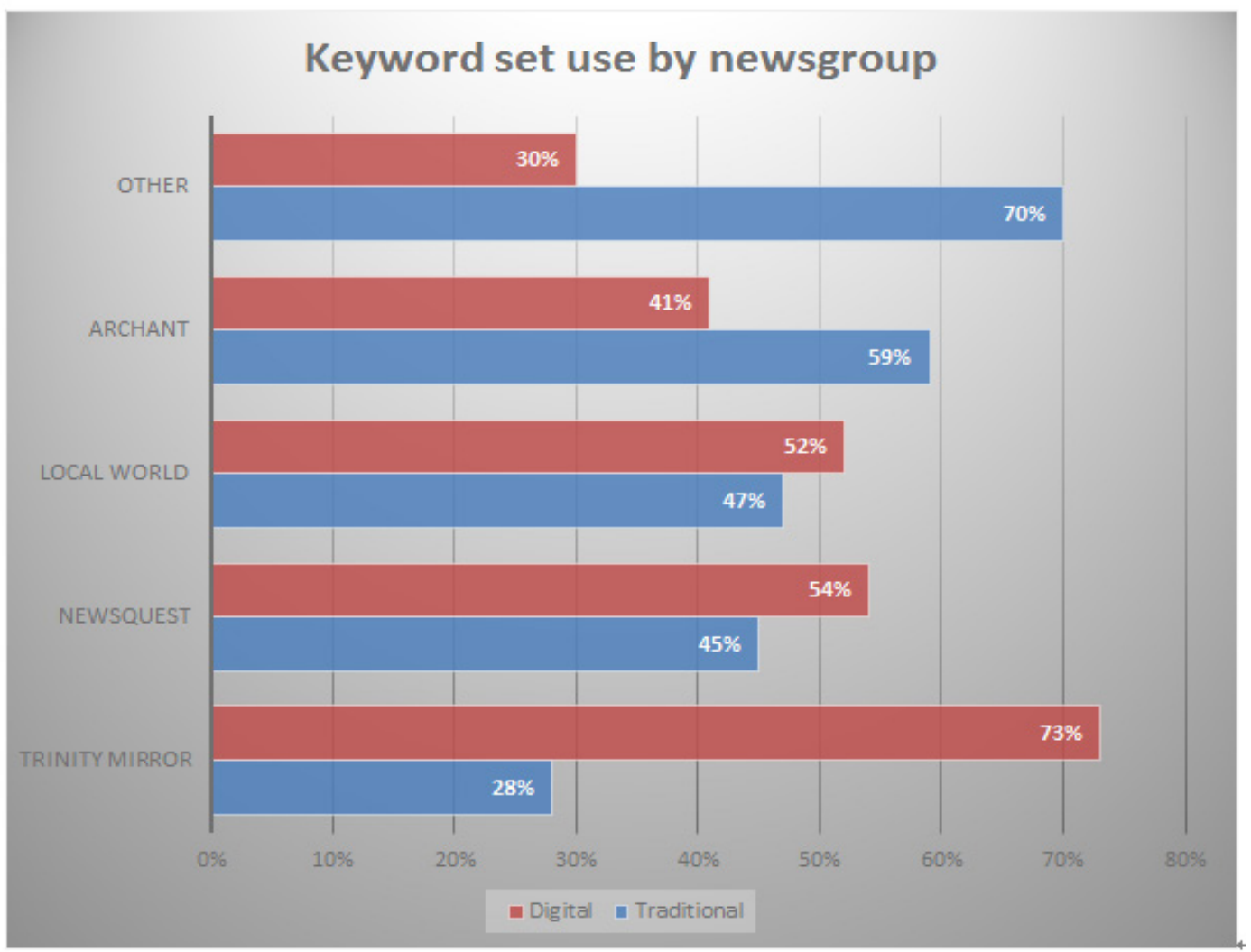

Figure 5.

The most recruited for role was that of a reporter - with 35 positions being advertised, followed by trainee reporters, with 34 jobs advertised. There were 9 specialist reporter roles, 8 editor roles, 5 newsdesk positions and 5 online journalist roles, there were 2 roles classified as 'other' and no deputy editor roles were advertised.

\section{Discussion}

Perhaps now the tipping point has been reached.

The results of this research show quite clearly that a digital emphasis is taking precedence within the language of job advertisements for news journalist positions at local UK newspapers. From the advertisements analysed, the number of digital keywords used within the job descriptions far outweighed the number of traditional keywords, despite the range of keywords being used by employers being smaller by three.

Digital keywords have also proved to take precedence over traditional words due to their placement in the job descriptions. The top three keywords used first in advertisements were digital rather than traditional; with their primary placement suggesting they are regarded as more important by the authors of the job descriptions [29].

As noted by Shi and Bennett [30], while the ideal being represented in a job advert is best assessed by interview, the advertisement is an excellent method of advising candidates of the perfect skills and environment. This echoes Harper's [26] stance over job advertisements portraying the desired situation rather than necessarily the reality.

Therefore, it could be argued that the vast imbalance between digital and traditional skills within the adverts collected is indicating a desire for a newsroom driven by digital as much as the printed product, rather than factually demonstrating the current reality. This would back up the evidence found by Canter [12] who found writing and digital skills to be of equal value to traditional skills by employing editors. It would also demonstrate a significant change in attitude from earlier studies which suggested editors were more interested in traditional over digital skills possessed by potential candidates [2,4-5,9-10].

As noted previously, rather than describing specific skills, many keywords represent a skill or describe a knowledge required in the overall environment being described in the job profile. The most popular keywords certainly suggest an environmental quality, with the words 'online', 'digital', 'social media' and 'website' making reference to the priorities and products of the employing newspaper. The less used digital keywords are almost all more specific in identifying a digital skill, with 'code', 'podcast', 'Facebook' and 'Twitter' each identifying specific areas of expertise. This contrasts with the traditional keyword list - where specific skills such as 'NCTJ', 'driving licence', 'qualification' and 'shorthand' all rate more highly than other, more generic or environmental qualities or subjects.

This difference could be down to the fact that traditional journalism skills are easier to define. There are set qualifications which are either possessed or not possessed by 
a candidate, rather than criteria of more subjective 'desirabilities' as found in the digital list. It could also be down to the fact that while traditional skills have remained unchanged for years, digital skills are constantly evolving [31-32]. So, for example, while Facebook might have been the social media of 2014, What's App and Snapchat could be more representative of 2015 - by using such specifics a job profile writer would find themselves potentially limiting candidates based on an ever-changing measurement. A similar suggestion was made by a 2016 Tow-Knight Center for Entrepreneurial Journalism study [33] which found that "Transformational" skills - skills which were new and adaptable to change - were more highly rated by media employers in the USA than "Foundational" skills, which were the traditional skills "long held" by journalists. So, for example, in terms of the way digital skills are referenced in job advertisements, a more generic term such as 'social media' allows for flexibility in the future and invites candidates with a wide range of skills in the area. As noted by Drozdowski [29] this allows for a wider pool of applicants and therefore talent to choose from.

This 'flexibility and adaptability' of reporters was also mentioned by employing regional newspaper editors at the NCTJ's Journalism Skills Conference 2015 [34]. But while new and adaptable journalistic skills were being sought, as reflected by this study, editors also wanted traditional skills like shorthand to remain prevalent.

This study also contradicts editors' claims that the NCTJ is no longer relevant [12]. The NCTJ qualification came high up the list of skills both mentioned in the advertisements, but also in terms of the importance placed on that skill - with the term being placed joint first alongside 'print' in terms of traditional word placement. Value was also placed on 'driving licence', but less emphasis was placed on 'shorthand' and the NCE and NQJ qualifications. As suggested by Stencel and Perry [36] the lesser emphasis placed on these traditional skills could be due to an assumption that these skills are already in place - reflecting 'an oversupply rather than lack of demand'

It should not be ignored that it is the larger newsgroups in the UK which have placed the most emphasis on digital language, with smaller groups and independently-owned titles still continuing to focus more on traditional skills. It must also be acknowledged that the data pool of smaller titles is limited by the few number of times they have individually placed adverts in this period, meaning the results have to be treated with some caution.

The overall difficulty with the results of this one-off study is that they project a limited viewpoint from a relatively short time period - a snapshot of the situation rather than a full landscape. That is why, to ascertain if the results can project a real change in the way editors and newspaper employers are thinking, this study is the first part of a four-year longitudinal study. Advertisements will be collected from the same website from November to January every year until 2017 to track any long-term changes and trends.
This study will also be complimented by a survey of local news journalists and interviews with news journalists of varying levels to assess what skills and qualities are most values in practice.

\section{Conclusions}

"The tide is flowing inexorably from an old media towards the Internet, with a force that media managements cannot control." [15].

A decade ago there was resistance and denial against the influence of internet and digital technology in newsrooms then it became clear that the issue, and all of the prizes and problems carried by digital innovation, were not going to fade away. At that point newspapers started to accept and work with the opportunities provided [35-36]. But with the vast ocean of possibilities opened up by the internet and digital innovation, the question being asked by newspaper groups before taking the plunge was "in which direction should we swim?" $[15,36]$.

Perhaps the results of this study demonstrate that local newspapers in the UK have gone from dipping their toes in the water to diving in and embracing a future where digital has the potential to dominate over print in terms of audience use and, therefore, a potentially sustainable business model $[8,37]$.

As acknowledged by Stone [36]:

"A multitude of revenue-making opportunities await media companies in the 21 st Century. The science of diversifying the revenue model is being honed in order for publishers to hedge against sliding print revenues and circulations. Opportunities online are abundant, but solid strategies are necessary to take advantage of them."

While it must be noted that there are still question marks over how digital revenue can generate enough money to offer survival to newspapers, it is clear from this research that publishers are no longer in the "rejection and resistance" stage of the cycle as described by Stone [36] but have now moved onto the "new orientation and engagement" phases.

The results, if compared to other similar studies, show a greater emphasis on digital skills than ever before. The prevalence and placement of digital keywords demonstrate how the industry is changing. They show a desire to embrace and exploit the digital world while continuing to produce news with traditional values, employing traditional skills.

But while this outcome is new, the prevalence of digital keywords are not overly surprising as the results follow in the path laid by recent research which has shown increasing favorability towards digital over the traditional skills in new recruits [11-12].

As with all research, caution must be voiced. Until further comparable study is undertaken either through further annual data collection or follow-up surveys and interviews, the results can only be relied on to demonstrate the ideals 
and values [26-27] of local newspapers in the UK, rather than solid realities within the newsroom environment.

However, as a starting point, this research suggests a real shift in changing attitudes. It indicates the digital tipping point has been reached; bringing with it a potential change in methods, motives, industry training and, ultimately, a shift in the future of local newspapers in the UK.

\section{Acknowledgements}

Catherine O'Connor and Prof Graham Roberts, Dr Chris Paterson and Dr Julie Firmstone for their advice and support.

\section{REFERENCES}

[1] Russell B. The forms of power. In: Lukes S, editor. Power. Oxford: Basil Blackwell Ltd. 1987.

[2] Pierce T, Miller T. Basic Journalism Skills Remain Important in Hiring. Newspaper Research Journal. 2007. Fall; 28 (4): 51-61.

[3] Fahmy S. How Online Journalists Rank Importance of News Skills. Newspaper Research Journal. 2008. Spring; 29 (2): 23-39.

[4] Carpenter S. An Application of the Theory of Expertise: Teaching Broad and Skill Knowledge Areas to Prepare Journalists for Change. Journalism \& Mass Communication Educator. 2009. Sep; 64 (3): 287-304.

[5] Russial J, Santana A. Specialization Still Favored in Most Newspaper Jobs. Newspaper Research Journal. 2011 Jun 1; 32(1): 6-23.

[6] Singer J B. Strange Bedfellows? The Diffusion of Convergence in Four News Organizations. Journalism Studies. 2004. Winter; 5 (1): 3-18.

[7] Boczkowski P. The Construction of Online Newspapers: Patterns of Multimedia and Interactive Communication in Three Online Newsrooms. International Communications Association. 2003. Annual Meeting, San Diego, CA.

[8] ONS. Internet Access - Households and Individuals; 2014. Office for National Statistics; 2014. [Accessed Aug 17 2015]. http://www.ons.gov.uk/ons/rel/rdit2/internet-access---househ olds-and-individuals/2014/stb-ia-2014.html.

[9] Cleary J, Cochie M. Core Skill Set Remains Same in Newspaper Job Ads. Newspaper Research Journal. 2011. Winter; 32 (4): 68-82.

[10] Gunter J. Editors Still Prize Traditional Skills, Finds NCE Review. Journalism.co.uk, 2011. [Accessed Aug 17 2015]. https://www.journalism.co.uk/news/editors-still-prize-traditi onal-skills-finds-nce-review/s2/a545729/.

[11] Nikunen K. Losing My Profession: Age, Experience and Expertise in the Changing Newsrooms. Journalism. 2014. Oct; 15 (7): 868-88.

[12] Canter L. Chasing the Accreditation Dream: Do Employers Value Accredited Journalism Courses. 2014. www.jobs.ac.uk.
[Accessed Aug 8 2015]. https://blogs.jobs.ac.uk/all-things-re search/files/2015/07/Journalism-education-issue-4-1-1.pdf.

[13] Sheller M. News Now. Journalism Studies. 2015. Jan; 16(1): 12-26.

[14] Deuze M. What Is Journalism? Journalism. 2005. Nov; 6 (4): 442-64.

[15] Curran J. The Future of Journalism. Journalism Studies. 2010. Fall; 11 (4): 464-76.

[16] Robinson S. "Journalism as Process": The Organizational Implications of Participatory Online News" Journalism \& Communication Monographs. 2011. Sep; 13 (3): 137-210.

[17] Currah, A. Media: Clickstream Journalism. Prospect. 2009. 157: 68-69. [Accessed July 28, 2016]. Available from: http://www.prospectmagazine.co.uk/science-and-technology /clickstreamjournalism

[18] Usher N. Going Web-First at the Christian Science Monitor: A Three Part Study of Change. International Journal of Communication. 2011. Academia. [Accessed July 28, 2016]. Available from: http://www.academia.edu/2492657/Going Web-First_at_the_Christian_Science_Monitor_A_three-part study_of_change

[19] Daulerio AJ. Gawker Will Be Conducting an Experiment, Please Enjoy Your Free Cute Cats Singing and Sideboobs. Gawker.com. 2012. [accessed Aug 17 2015] Available from: http://gawker.com/5878065/gawker-will-be-conducting-an-e xperiment-please-enjoy-your-free-cute-cats-singing-and-side boobs

[20] Dickinson R. The Use of Social Media in the Work of Local Newspaper Journalists. Future of Journalism Conference. 2011. Cardiff University, Cardiff, Wales: Cardiff School of Journalism, Media and Cultural Studies.

[21] Quandt T. (No) News on the World Wide Web? Journalism Studies. 2008.9 (5): 717-38.

[22] Domingo D, Quandt T, Heinonen A, Paulussen S, Singer J B, and Vujnovic M. Participatory Journalism Practices in the Media and Beyond. Journalism Practice. 2008. 2 (3): 326-42.

[23] Newman N. The Rise of Social Media and Its Impact on Mainstream Journalism. Reuters Institute for the Study of Journalism. 2009. [accessed August 17 2015] Available from http://reutersinstitute.politics.ox.ac.uk/publication/rise-social -media-and-its-impact-mainstream-journalism

[24] Bradley P. Data, Data Everywhere. Legal Information Management. 2014. 14 (4): 249-52.

[25] McAthy R. Trinity Mirror to Set up Data-Driven 'Digital Journalism Unit'. Journalism.co.uk. 2013. [Accessed August 17 2015]. Available from: https://www.journalism.co.uk/ne ws/trinity-mirror-to-launch-data-driven-digital-journalism-u nit/s2/a552493/.

[26] Harper R. The Collection and Analysis of Job Advertisements: A Review of Research Methodology. Library \& Information Research. 2012. 36 (112): 29-54.

[27] Johnson A, Winter P A, Reio Jr T G, Thompson H L, Petrosko J M. Managerial Recruitment: The Influence of Personality and Ideal Candidate Characteristics. Journal of Management Development. 2008. 27 (6): 631-48.

[28] De Cooman R, Pepermans R. Portraying Fitting Values in Job Advertisements. Personnel Review. 2012. 41 (2): 216-32. 
[29] Drozdowski M. When All Goes Right. Chronicle of Higher Education. 2007. 53 (26): C3-C3.

[30] Shi N, Bennett D. Information Systems Management Positions - a Market Perspective. Work Study. 2000. 49 (7): 275.

[31] Hogan B, Quan-Haase A. Persistence and Change in Social Media. Bulletin of Science, Technology \& Society. 2010. 30 (5): 309-15.

[32] Hodder A. Change of Pace. Benefits Canada. 2012. [Accessed August 17] Available from: http://www.benefitscanada.com/ wp-content/uploads/2012/06/NM-Editorial.pdf.

[33] Stencel M, Perry K. Superpowers - the digital skills media leaders say newsrooms need going forward. Webpage. [Accessed 28 July, 2016] Available from http://towknight.or $\mathrm{g} /$ research/superpowers/
[34] NCTJ. Trainee journalists must be prepared for a constantly changing news environment says Birmingham regional editor. Webpage. [Accessed July 28, 2016] Available from: http://www.nctj.com/latestnews/Traineejournalistsmustbepre paredforaconstantlychangingnewsenvironmentsaysBirmingh amregionaleditor

[35] Canter L. The Interactive Spectrum: The Use of Social Media in UK Regional Newspapers. Convergence. 2013. 19 (4) 472-95.

[36] Stone M. New Revenue Strategies. Shaping the Future of the Newspaper. A World Association of Newspapers Project. 2006.

[37] BBC. Digital News Catches up with Papers in Uk, Ofcom Says. 2014. [Accessed July 28 2016]. Available from: http://www.bbc.co.uk/news/technology-28013959 